\title{
Dentists' chair to be paraded across the skies of London
}

A group of dentists has launched a crowdfunding page to raise capital for a 'baby blimp' of the General Dental Council (GDC) chair.

The news, first reported by Factually Accurate Knowledgeable Entertainment (FAKE) network, suggests 12 dentists have set the challenge throughout the 12 days of Christmas in order to raise festive cheer amongst their stricken colleagues.

The report also suggests the blimp - not dissimilar in nature to the Donald Trump and Sadiq Khan ones displayed in London earlier this year - will be paraded along the capital's Wimpole Street and Harley Street before making its way to Skipton House, where the floating effigy will have its mouth put back in the body.

The reported target set by the group is $£ 10,680$ - 12 times the annual retention fee (ARF).

A spokesperson for the group told the British Dental Journal: 'This has been some time in the making. We are of the belief that the General Dental Council is full of hot air, and what better way to reflect this to the wider dental community than to launch a blimp.

'We feel confident that with the support and donations from a number of

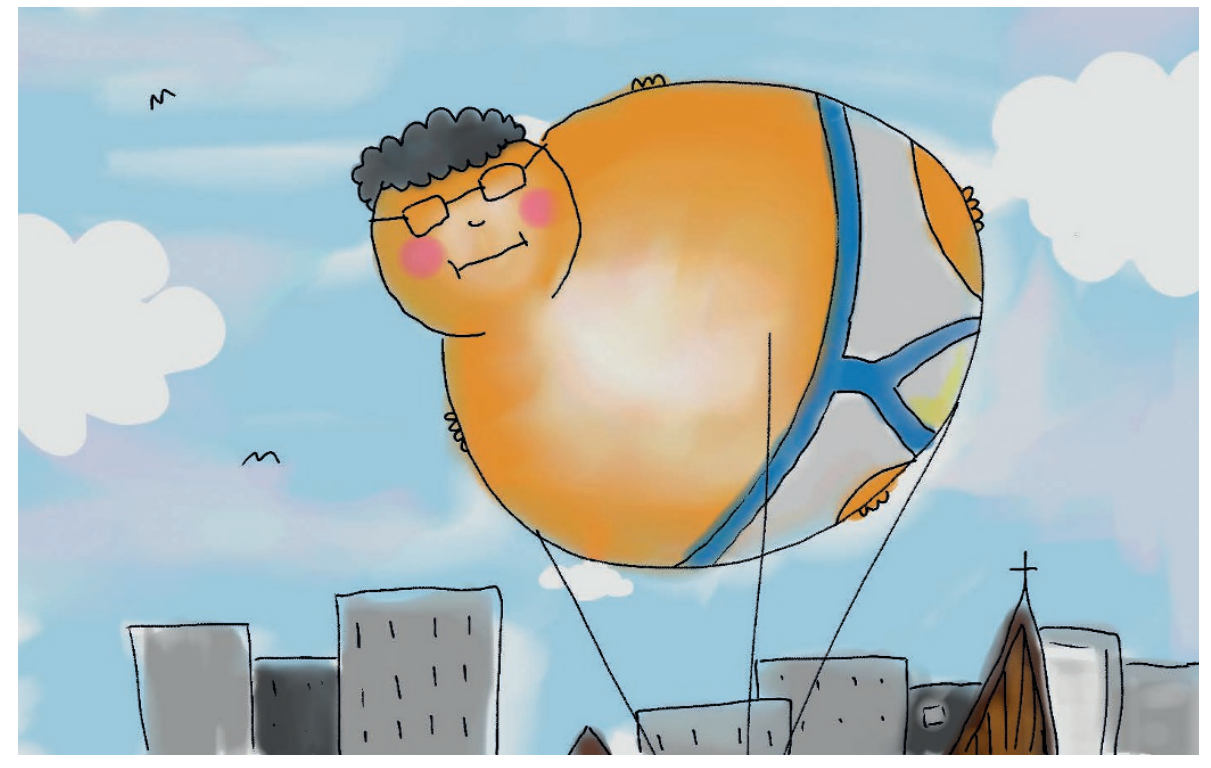

organisations we will be able to cover our annual retention fees. There is talk of us subsequently raising money for our legal fees once the regulator calls us to the location of the parade for a fitness to practise case, but that's for another day. A year's ARF will do just fine, for now.

Forums are already rife with members of the profession pledging their support. One thread suggested they will claim three UDAs for attending the parade, with others simply saying their zero-hour contracts will finally come in useful.

'A number of people on a particular forum for dentists have started a rumour that this blimp is an actual chair', the spokesperson added. 'At this stage we cannot confirm or deny that rumour, as we feel it would be better to spring a surprise at the last minute.'

The BDA was unavailable for comment.

DENTISTS ON FILM

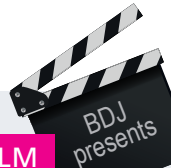

\section{Rudolph the Red-Nosed Reindeer (1964)}

H. S. Brand of the Academic Centre for Dentistry Amsterdam, and movie buff, continues his series of columns on films featuring dentists with Rudolph The Rednosed Reindeer, directed by Larry Roemer.

At the North Pole, all elves are busy making toys, except one. This is Hermey who explains to the foreman that he does not like to make toys because someday he would like to be a dentist.

He takes a thick dentistry book from under the table, saying: 'I've been studying. It's fascinating. You've no idea. Molars and bicuspids and incisors.'

The foreman bluntly objects, saying: 'Now listen, you. You're an elf, and elves make toys. Now get to work!'

However, Hermey also does not show up at the rehearsal of a new Christmas song. He is busy carefully hitting the teeth of a doll with a hammer saying: 'Now, this won't hurt a bit.'

The foreman is angry again that Hermey is fixing these dolls' teeth and says: 'We don't need any chewing dolls. A dentist! Good grief!'
Feeling sad, Hermey leaves the Santa Claus' castle. Outside he meets Rudolph, a reindeer who also considers himself a misfit because of his glowing red nose.

After several adventures together, they end up in the cave of the Abominable Snow Monster. When the snow monster is temporarily unconscious after a lump of ice has hit his head, Hermey quickly extracts all the monster's teeth with a pincer, saying: 'Don't let this big blowhard scare you anymore. He's nothing without his choppers.'

Hermey and Rudolph return as heroes to Santa Claus' castle. The foreman promises Hermey that he can open a dentist's office next week, after Christmas. Hermey immediately asks the foreman to open his mouth.

'Oh, dear,' he says. 'I'll set up an appointment for you, a week from Tuesday'.

Rudolph gets to lead Santa Claus' team of reindeer. 